\title{
CATOLICISMO E TRADIÇÕES ORIENTAIS: ENFOQUE INTRODUTÓRIO SOB O PARADIGMA DA ORIENTALIZAÇÃO
}

\author{
Catholicism and Oriental Traditions: An Introductory Focus on the Paradigm of \\ Orientalization
}

Renan Baptistin Dantas ${ }^{1}$

\section{Resumo}

Este trabalho parte de questionamentos que acompanham as reflexões iniciais de minha pesquisa de mestrado, na qual investigo interfaces entre membros e grupos oficialmente ligados a ICAR (Igreja Católica Apostólica Romana) e filosofias e práticas orientais asiáticas. Observamos diferentes casos empíricos neste sentido, que entrelaçam elementos e significados tradicionalmente católicos e orientais (como Zen e Yoga) em experiencias hibridas, tais quais o "Zen Católico" e a "Yoga Cristã". Tendo em vista esse universo, nos propomos a discuti-lo a partir de uma revisão crítica da tese defendida pelo sociólogo Colin Campbell a respeito da "orientalização do ocidente" (1997), levando também em consideração processos de "(re)invenção de tradições" (HOBSBAWM, 1984) nele imbricados.

Palavras-chave: Catolicismo; Orientalização; Reinvenção de Tradição

\begin{abstract}
This work starts from an inquiry that accompanies the initial reflections in my Master's research, where I investigate interfaces between members and groups officially linked to the RACC (Roman Apostolic Catholic Church) and eastern Asian philosophies and practices. We observed different empirical cases in this context, which intertwine traditionally Catholic and Eastern elements and meanings (such as Zen, Yoga, Meditation) in hybrid experiments, like "Catholic Zen" and "Christian Yoga." In view of this universe, we propose to discuss it based on a critical review of the thesis defended by sociologist Colin Campbell on the "orientalization of the West" (1997), as well as processes of "(re) invention of traditions" (HOBSBAWM, 1984) imbricated therein.
\end{abstract}

Key-words: Catholicism. Orientalization. Reivention of Tradition

\footnotetext{
${ }^{1}$ Licenciado em Ciências Sociais pela Universidade Estadual de Campinas (UNICAMP). Mestrando em Antropologia Social (UNICAMP.). Pesquisador do Laboratório de Antropologia da Religião LAR/UNICAMP). Lattes: http://lattes.cnpq.br/93476445333498227.
} 


\section{Introdução}

É visível no campo religioso contemporâneo global o surgimento de fenômenos empíricos que em seu conteúdo são formados pelo intercruzamento de formas de religiosidade cristãs/católicas e elementos de religiosidades, filosofias e terapêuticas tipicamente orientais asiáticas, oriundas de tradições do Extremo Oriente e da Índia, como Budismo, Taoísmo, Hinduísmo, Yoga, Reiki e Zen. Este é o tema fundamental da pesquisa de mestrado iniciada no primeiro semestre de 2019 junto ao Departamento de Antropologia Social da Universidade Estadual de Campinas (UNICAMP), da qual o presente trabalho é uma decorrência introdutória. Assim, pretendemos incialmente delimitar o escopo empírico dos fenômenos socioculturais sob os quais se pretende investigar, inclusive etnograficamente.

Entende-se que fenômenos deste tipo, estão ligados a processos de globalização da cultura, nos quais práticas e visões de mundo participam de um trânsito mundial, gerando fluxos, fronteiras e híbridos, facilitando experiencias que em seu bojo, contemplam elementos de ambas as partes da tradicional divisão do mundo: "oriente" e "ocidente". Este aparenta ser o caminho de diferentes experiencias contemporâneas, localizadas na configuração de "espaços comuns de sentido" (CAMURÇA, 2000, p. 97). Espécies de "zonas francas", "lugares simbólicos" onde distintos sistemas e agentes religiosos e espirituais podem acessar e experimentar avançar a fragilidade das fronteiras de seus respectivos sistemas de origem, consumindo, ou até mesmo incorporando alguma coisa proveniente de outro sistema. Como em um processo de "ida e volta", observa-se tanto uma "decontextualização de aspectos de uma tradição", quanto a "(re)invenção" das tradições importadoras de elementos alheios.

Em certo sentido, estas situações podem ainda estarem ligadas ao que se denominou "crise das instituições produtoras de sentido" (BRANDÃO, 1994). Vítimas do pluralismo religioso e secular contemporâneo e seu aspecto de competição - sua dimensão de "mercado" por assim dizer - instituições tradicionais, como a Igreja Católica Apostólica Romana (ICAR) e as igrejas protestantes históricas (Batista, Presbiteriana, Luterana, etc), sofrem com a perda do controle e influencia hegemônica sobre a sociedade civil. Neste "novo mundo", o catolicismo declina numérica e hegemonicamente, e para se reerguer, tenta tanto copiar os adversários - como no caso do Pentecostalismo 
Evangélico e (em termos vulgares) seu correspondente católico: a Renovação Carismática Católica (RCC) - quanto resgatar elementos esquecidos em sua tradição milenar de disputas teológicas e culturais.

Seguindo a trilha deixada por Colin Campbell (1997) a respeito da "ousada" e polêmica tese sociológica de que o Ocidente estaria sofrendo um processo de "orientalização", pretendemos aqui, tensionar objetos empíricos sob esse prisma. O sociólogo inglês adverte para um caminho que vai muito além da difusão de métodos e religiões asiáticas nos países ocidentais, implicando na substituição do paradigma ético e espiritual (a teodiceia) tipicamente ocidental, baseado na transcendência pelo paradigma ético espiritual tipicamente oriental, pautado na imanência como forma de teodiceia. Tendo em vista o inegável aspecto "oriental" de nosso objeto de estudo, o caminho analítico trilhado por Campbell nos intui questionamentos: poderíamos falar, a partir de certos casos, em um catolicismo que se orientaliza? Quais as potencialidades analíticas dessa linha teórica, que anuncia uma "imanentização do sagrado"?

\section{Entrelaçamentos entre catolicismo e práticas orientais asiáticas}

Segundo o trabalho de Thomas Csordas sobre as "modalidades de transcendência transnacional" (2007), os principais meios através dos quais se deu a globalização das religiões e religiosidades, basicamente foram: as ações missionárias, a imigração populacional, a mobilidade internacional viajante de indivíduos e as mediações permitidas a partir dos meios de comunicação como a internet. Assim, observamos que as conexões entre práticas e filosofias espirituais orientais da Ásia e contextos ocidentais, europeus ou americanos, fundamentalmente seguem movimentos semelhantes. Não é nosso objetivo aqui nos aprofundarmos no conhecimento destes processos históricos. Porém, no momento nos basta reconhecer que a entrada de filosofias e religiosidades como Yoga e Zen Budismo no Ocidente, basicamente seguiu alguma dessas direções apontadas por Csordas. Nossa discussão neste trabalho, encara basicamente as interpelações destas duas tradições - Yoga e Zen - ao catolicismo, a partir da ênfase em experiências católicas formadas por um certo hibridismo entre tradições, geralmente “versões cristãs/católicas" de práticas tipicamente orientais. 
Entendemos que, a abertura teológica inclusivista ${ }^{2}$, empreitada pela ICAR, que se deu principalmente após o Concílio Vaticano II (1962-1965), evento histórico que marca uma inflexão pastoral na prática da Igreja, permitiu desenvolvimento cada vez maior de experiencias de diálogo e troca com diferentes tradições espirituais.

O documento conciliar que materializa inquietações da ICAR neste sentido é a declaração "Nostra Aetate: sobre as relações da Igreja Católica com as religiões não cristãs”. Nele a Igreja assume a necessidade de se dialogar com as demais religiões e de ter diante delas uma atitude positiva, reconhecendo seus valores. Quanto às religiões orientais Hinduísmo e Budismo, o documento diz:

a Igreja Católica nada rejeita do que há de verdadeiro e santo nestas religiões. Considera ela com sincera atenção aqueles modos de agir e viver, aqueles preceitos e doutrinas. Se bem que em muitos pontos estejam em desacordo com os que ela mesma tem e anuncia, não raro, contudo, refletem lampejos daquela verdade que ilumina a todos os homens. (...) Exorta, por isso seus filhos a que, com prudência e amor, (...) reconheçam, mantenham e desenvolvam os bens espirituais e morais, como também os valores sócio-culturais que entre eles se encontram (NA, 1965, 2, 2-3).

Este contexto de abertura facilitou a formação de uma série de "buscadores do diálogo" (TEIXEIRA, 2015), sacerdotes católicos que buscaram vivenciar simultaneamente as vocações religiosas cristãs/católicas e outras, tais quais as orientais hindus ou budistas, como nos casos do monge beneditino francês Henri Le Saux, que vivenciou o hinduísmo, o jesuíta alemão Hugo Enomiya Lassalle e o trapista Thomas Merton, que se aproximaram do budismo zen..

Yoga é uma prática e filosofia tradicional indiana, que utiliza um conjunto de técnicas psicofísicas, e é formada por diferentes linhas e correntes. Historicamente, sua relação com experiências católicas se deu através de missionários, "mediadores culturais" (MONTERO, 2006), frequentemente ligados a ordens eclesiásticas, como o caso de alguns jesuítas e beneditinos. Sua ligação com a religião hindu, originalmente é inegável, e é geralmente advertida por grupos católicos mais conservadores e tradicionais que a enquadram como uma prática panteísta e demoníaca. Porém, por outro lado o que muitos dizem - inclusive católicos praticantes - é que ela é uma dimensão acessória, e as técnicas

\footnotetext{
${ }^{2}$ Concepção teológica que reconhece "Sementes do Verbo" em outras tradições espirituais e filosóficas e a possibilidade de "salvação fora da igreja".
} 
yogues (asanas, as posturas físicas, pranayamas, exercícios respiratórios e as visualizações) podem ser praticadas de maneira laica e não espiritualizada.

Fato é que, uma das primeiras aproximações que se tem notícia entre experiencias católicas e yoga, ocorreu em 1960 - auge da contracultura, "momento decisivo" para o desenvolvimento da teodiceia oriental no ocidente segundo Campbell (1997) - com o monge beneditino francês Jean MarieDechanet, que escreveu um livro intitulado "Ioga para Cristãos”. Posteriormente, na argentina outro jesuíta, Ismael Quiles, estudou yoga a fundo, e num livro "Qué es él yoga” publicado em 1987, desenvolveu reflexões para um “yoga Cristiano". Além de fundar na Universidade Católica Del Salvador o curso de "Tecnitura Universtitaria en Yoga". Pe. Cesar Augusto Davila Gavilanes, no Equador também falou em “yoga cristiano" e fundou a "Asociación Escuela de Autorrealización”, com centros no Panamá, Colômbia e Itália. Padre Joe Pereira, sacerdote jesuíta indiano que com frequência vem ao Brasil conduzir "workshops" sobre Iyengar Yoga, e classifica Jesus como um “iogue” (DANTAS, 2018).

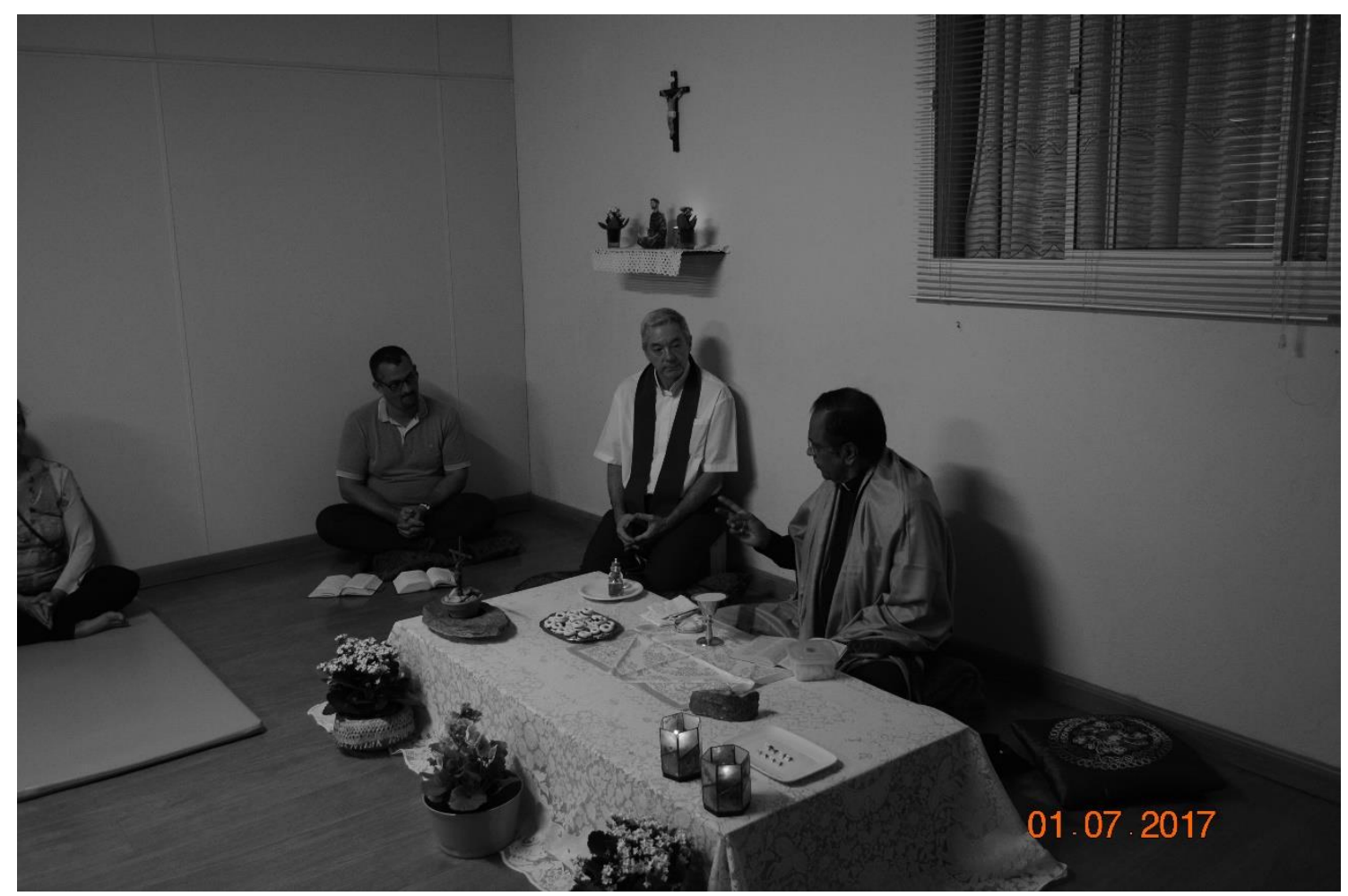

Missa indiana (Ribeirão Preto-SP), com o jesuíta indiano Joe Pereira. 
Dentre os casos de experiencias católicas com yoga, destacamos a yoga cristã criada pelo padre jesuíta Haroldo J. Rahm, definida por ele como "uma arte e uma ciência ascética para conhecer a Divina Majestade" (RAHM, 2007, p. 21), ou seja, uma pratica que leva o a experiencia mística, união individual com Deus e consigo mesmo - a "unio mystica" weberiana, na qual o indivíduo se torna "receptáculo do divino". Nesta prática, além dos asanas e pranayamas o padre pega da tradição yogue o reconhecimento dos chakras, centros de energia vital no formato de vórtices, dispostos ao longo da coluna vertebral. Neste sentido, ele associa estes conceitos metafísicos a algumas noções tradicionais do catolicismo, como por exemplo quando compara a noção de prana “força vital” para os yogues indianos - e o "sopro do Espírito (cf. Gn 1,2)" (RAHM, 2007, p. 109), e diz que "o chakra do coração na meditação e na contemplação do amor Divino é para iogues cristãos que procuram o casamento místico. Procuram receber o selo do Espírito Santo" (RAHM, 2007, p. 71). Observa-se assim um exercício especulativo e hermenêutico e inventivo, de aproximação de "ilhas de significados" e cosmologias distintas, cristãs/católicas e indianas yogues.

Sobre seu processo criativo, padre Haroldo

Eu li muito sobre yoga, yoga indiana que Patanjali (codificador do Raja Yoga, yoga do controle mental - parêntesis nosso) escreveu antes da chegada de Jesus cristo, e eu mudei as palavras destes homens que são muito boas e espirituais, mas eu apliquei as idéias da bíblia e Santo Inácio nos exercícios espirituais e cristianismo e por isso se chama yoga cristã [Entrevista, Haroldo Rahm, Campinas - SP,07/07/2016] (DANTAS, 2018, p. 55).

Como podemos perceber, o padre associa os elementos da yoga indiana com parte de seu repertório católico, em especial com os Exercícios Espirituais de Santo Inácio de Loyola, conjunto de técnicas psicológicas e espirituais místicas que exercitam a memória, o entendimento, a imaginação, a contemplação, a vontade e o controle e aplicação dos sentidos, desenvolvidas pelo fundador da Companhia de Jesus. Neste ponto, vemos algo recorrente nos processos de diálogo e incorporação de técnicas orientais a prática católica, o resgate de tradições, ou ainda, a "(re)invenção" (HOBSBAWM, 1984) dessas tradições católicas esquecidas, ou pouco populares. De tal forma, o padre chega a afirmar que:

Santo Inácio e São João da Cruz, embora sem saber, foram os primeiros dois santos a unir a espiritualidade do Ocidente com a do Oriente. Frequentemente, esquecemos que Jesus Cristo era judeu e vivia no 
Oriente Médio. Tais idéias orientais, no começo de minha carreira, levaram-me a um ecumenismo de pensamento e a usar uma terminologia mais pneumática (RAHM, 2011, p. 139).

Notável a construção de um orientalismo no discurso desse jesuíta, o que nos intui a existência de um discurso orientalista católico, gerado a partir do encontro de sacerdotes católicos e a materialidade ritual de certas tradições orientais. Caberia ainda discutirmos com mais profundidade, não só a relação catolicismo e yoga, mas também com a tradição Zen, ligado principalmente ao Budismo japonês e que também se conecta à experiencias católicas de diálogo e hibridismo. Por enquanto, nos basta citar alguns casos, como, dentre outros o já citado Thomas Merton, um monge que fez paralelos entre as tradições, o de Aelred Graham monge e teólogo beneditino inglês que em 1963 escreveu o livro "Zen Católico" e do também já classificado por Teixeira (2015) como "buscador do diálogo", Hugo Enomiya Lassalle, que viveu muitos anos no Japão experenciando diretamente o Zen Budismo, tornando-se inspiração da fundação argentina Zendo Betania, caracterizada por combinar

prácticas rituales budistas y católicas al mismo tiempo que articula ideas y símbolos de estas dos cosmovisiones, poniendo en juego un proceso de traducción de las enseñanzas y una reelaboración de las prácticas zen a un lenguaje y un régimen de corporalidad asequible a personas que no se hallan familiarizadas con dichas prácticas y representaciones (PUGLISI; CARINI, 2017, p. 220).

\section{Orientalização do catolicismo?}

Preocupado em anunciar o desvelar de uma "nova ética para o século XXI", o sociólogo Colin Campbell defendeu a tese de que o ocidente estaria passando por um processo de "orientalização". Tal processo basearia-se em um progressivo abandono da visão tipicamente Ocidental caracterizada pela transcendência e conseqüente adoção da visão tipicamente oriental marcada pela Imanência. Neste sentido, falar em orientalização seria mais do que

discutir simplesmente a introdução de idéias e valores religiosos do Oriente; é referir-se ao processo pelo qual a concepção de divino tradicionalmente ocidental e suas relações com a humanidade e o mundo é substituída por aquela que tem predominado por longo tempo no Oriente (CAMPBELL, 1997, p. 7). 
Assim, é partindo das considerações de Weber a respeito do problema da teodiceia, ou seja, do paradigma cultural dominante que informa pensamento e prática, e voltado para religião se refere aos "caminhos para Deus" e o "problema do mal no mundo"3 que Campbell anuncia a orientalização.

- A implicação religiosa da troca de teodicéia (visão de mundo) é a quebra da dualidade homem-divindade, que anula a crença em um Deus pessoal e transcendente da tradição judaico-cristã ocidental, e recupera a visão de um Deus impessoal e imanente, respaldando a crença intimamente ligada a Nova Era segundo a qual Deus "é o fundamento ou alma, a 'semente' ou a 'centelha' de todas as criaturas" (CAMPBELL, 1997, p. 11), e se interpenetra no mundo cotidiano.

Ainda como argumenta Campbell, este processo

não tem que depender simplesmente de uma importação de idéias exógenas, mas pode ser entendido como facilitado pela presença de uma tradição cultural nativa ao Ocidente. De fato, existem pelo menos duas outras dessas tradições 'nativas'que podem ser identificadas como importantes para a eclosão da alternância histórica de uma teodiceia ocidental para uma teodiceia oriental (CAMPBELL, 1997, p. 13).

Quanto a essas tradições nativas ocidentais, Campbell se refere ao Neo-Paganismo e a Nova Era. Porém, além destas tradições, o autor cita outras como o Movimento Ambientalista, e deixa em aberto o argumento de que uma base para o processo de orientalização já existia em formas nativas do ocidente. É nesta direção que podemos enquadrar os resgates de tradições místicas católicas (como a dos Exercícios Espirituais inacianos), como formas religiosas nativas do ocidente, que a partir do deflagrado processo de propagação de um orientalismo cultural, principalmente a partir dos ventos contra culturais da década de 60, ganham força e visibilidade.

Portanto, nosso objetivo neste ensaio, é de maneira introdutória pontuar e tencionar o argumento de Campbell, tendo e vista alguns casos etnográficos observados no Brasil, Argentina, Estados Unidos e outros países, que revelam como foi definido pelo antropólogo argentino Rodolfo Puglisi, "paralelismos cosmológicos y experienciales entre el misticismo cristiano y saberes y tecnologías religiosas orientales" (PUGLISI, 2016, p. 67).

\footnotetext{
${ }^{3}$ Peter Berger define teodiceia como uma "tentativa de se fazer um pacto com a morte" $(1985$, p. 92$)$
} 
Espremendo o argumento de Campbell, o que "compramos" dele analiticamente, deixando de lado um certo perigo do exotismo dualista, que com arbitrariedade e certa artificialidade separa oriente e ocidente, trata-se sem dúvida da ascensão da imanência enquanto teodiceia hegemônica da prática cristã, tanto católica quanto evangélica. Os pentecostais e carismáticos em seus modos de ser também respondem a certos imperativos informadores das interfaces cristãs/católicas e orientais/asiáticas; vide a centralidade de engajamento do corpo e dos sentidos nas experiencias subjetivas com o Espírito Santo. Isso não significa que a transcendência foi deixada de lado nesses casos, mas pensando com a chave do dualismo (imanência x transcendência), observa-se uma co-habitação, quando não um prevalecimento de formas mais subjetivas de relação com o sagrado católico cristão.

\section{Considerações finais}

É fundamental levarmos em conta os limites categóricos da análise em questão. Para isso, recorremos à contribuição de Edward Said sobre o orientalismo enquanto processo de "construção do Oriente" a partir de uma relação de poder desnivelada, no qual quem fala, quem define muitas vezes é "o lado de cá", enquanto o "lado de lá", suposto "oriente", mantem-se calado, ao ser observado e descrevido como uma "peça no museu", ou talvez ainda como mais um item no "catálogo de borboletas" de Radcliffe Brown. O oriente geralmente é construído em relação de força com o ocidente, desempenhando papel de submissão. Buscamos assim nos advertir quanto as "cortinas de fumaça" e os "ponto cegos" do argumento da orientalização, que em alguns pontos é válido. Pois, assim como o próprio Said afirmou, o orientalismo também "não é uma fantasia avoada da Europa sobre o Oriente, mas um corpo criado de teoria e prática em que houve, por muitas gerações, um considerável investimento material” (SAID, 2007, p. 18).

Tendo em vista, portanto, a inegável cultura material enquadrada na conjunção de formas ocidentais cristãs/católicas e formas orientais asiáticas (budistas, hinduístas, taoistas, etc), arriscamos intuições para a hipótese de um "catolicismo orientalizado". Como consideração analítica que busca seguir a linha vivida pela tese da "orientalização", identificamos visões imanentes do divino já existentes dentro da tradição católica, alguns 
cultivados de maneira quase que "esotérica" - principalmente no que tange o sentido de conhecimento reservado a uma minoria - já que inclusive foram muitas vezes perseguidos - como nos casos dos Cátaros, Teilhard Chardin, São João da Cruz, Mestre Eckart e outros místicos.

Existe ainda uma linha de percurso dentro das pesquisas epistemológicas católicas, desenvolvidas nos âmbitos das universidades e suas congregações, que alimenta discursivamente a conceitualização orientalista. Oriente surge em alguns casos como um termo esponja, que absorve e equaliza investidas adversárias no que se refere ao controle cultural hegemônico.

Ademais, mesmo que talvez seja minoritário, a influência externa, de práticas orientais sob o catolicismo - que muitas vezes anda de mãos dadas com o vetor da religiosidade da Nova Era - pode ser argumentada, como em partes já foi (CAMURÇA, 2014). De tal forma, da mesma maneira como foi observado processos de orientalização tipicamente localizados em outras tradições religiosas contemporâneas como o NeoPentecostalismo (DA SILVA, 2011) e no Espiritismo, através da crença da reencarnação (CAMURÇA, 2000), este trabalho procura apontar para linhas típica-ideais orientais tendo em vista experiencias internas ao catolicismo.

\section{Referências bibliográficas}

BERGER, Peter L.; SAGRADO, O. Dossel. elementos para uma teoria sociológica da religião. São Paulo: Paulus, 1985.

BRANDÃO, Carlos Rodrigues. A crise das instituições tradicionais produtoras de sentido. Misticismo e novas religiões. Petrópolis: Vozes, v.1, p.23-41,1994.

CAMURÇA, Marcelo. O conceito de Reencarnação no Espiritualismo moderno: Entre o Círculo de Sãmsara e o Evolucionismo Positivista. Numen, v. 3, n. 1, 2000.

CAMURÇA, Marcelo Ayres. Espiritismo e Nova: Interpelações ao Cristianismo Histórico. Aparecida: Editora Santuário, 2014.

CAMPBELL, Colin. A orientalização do Ocidente: reflexões sobre uma nova teodicéia para um novo milênio. Religião e sociedade, v.18, n.1, p.5-22,1997. 
CSORDAS, Thomas. Modalities of transnational transcendence. Anthropological Theory, 7, pp. 259-272, 2007.

DANTAS, Renan B. Catolicismo, jesuitismo e yoga cristã através da trajetória de padre Haroldo J. Rahm, SJ. Monografia em ciências sociais/IFCH. Campinas, 2018.

DA SILVA, Janete Rodrigues. Movimento neopentecostal e neoesoterismo: um enfoque sob o paradigma da orientalização do Ocidente. Plural-Revista de Ciências Sociais, v. 18, n. 2, p. 135-160, 2011.

HOBSBAWM, Eric. Introdução: a invenção das tradições. A invenção das tradições, v. 3, p. 09-23, 1984.

MONTERO, Paula. Índios e missionários no Brasil: para uma teoria da mediação cultural. Deus na aldeia: missionários, índios e mediação cultural. São Paulo: Globo, p. 31-66, 2006.

PUGLISI, Rodolfo; CARINI, Catón Eduardo. Monjas y sacerdotes católicos como maestros zen. Historia de la escuela Zendo Betania. Revista Brasileira de História das Religiões, v. 10, n. 29, p. 217-236, 2017.

PUGLISI, Rodolfo. El encuentro del catolicismo y el budismo en las espiritualidades argentinas contemporáneas. Una mirada etnográfica a los grupos zendo betania. PUBLICAR-En Antropología y Ciencias Sociales, n. 20, 2016.

RAHM, Haroldo J. Yoga Cristã e Espiritualidade de Santo Inácio de Loyola. Edicoes Loyola,2007.

Esse Terrível Jesuíta!. São Paulo: Loyola; 2011

SAID, Edward W. Orientalismo: o Oriente como invenção do Ocidente. Editora Companhia das Letras, 2007.

TEIXEIRA, Faustino Luiz Couto; DIAS, Zwinglio M. Ecumenismo e diálogo interreligioso: a arte do possível. Editora Santuário, 2015. 